\title{
Studies on mcl-Polyhydroxyalkanoates Using Different Carbon Sources for New Biomedical Materials ${ }^{\dagger}$
}

\author{
Dana Miu' ${ }^{1,2}$, Mariana Gratiela Vladu ${ }^{2}$ and Sorin-Ion Jinga ${ }^{1}$ \\ 1 Faculty of Applied Chemistry and Materials Science, University Politehnica of Bucharest, 1-7 Gh. Polizu \\ Street, 01106 Bucharest, Romania; \\ 2 National Institute for Chemical Pharmaceutical Research and Development, 112 Vitan Ave, \\ 031299 Bucharest, Romania; \\ + Presented at the 24th International Electronic Conference on Synthetic Organic Chemistry, 15 November- \\ 15 December 2020; Available online: https://ecsoc-24.sciforum.net/.
}

Received: date;

\begin{abstract}
Polyhydroxyalkanoates (PHAs) are microbial homo- and copolymers of [R]- $\beta$ hydroxyalkanoic acids, produced by a wide variety of bacteria as an intracellular carbon and energy reserve. To obtain mcl-PHAs of microbial origin, we used a Pseudomonas spp. strain (from the National Institute for Chemical-Pharmaceutical Research and Development (ICCF) culture collection of micro-organisms), by varying the carbon sources and the precursors. In this work, assays were performed with fermentation media seeded with inoculum cultures of strain Pseudomonas putida in a proportion of $10 \%$. The influence on mcl-PHA production of carbon sources for strain development, hexanoate (C6), heptanoate (C7), octanoate (C8) and nonanoate (C9) acids, as polymers precursors, were analyzed. Due to their properties, similar to those of conventional plastics and their biodegradability, PHAs are suitable for many applications and for biomedical materials useful in surgical sutures, tissue engineering and drugs carriers, which leads us to the deepening of the study of obtaining micro/nanofibers by the electrospinning method.
\end{abstract}

Keywords: polyhydroxyalkanoates; bioprocess; biomaterials; electrospinning

\section{Introduction}

Polyhydroxyalkanoates (PHA) are microbial homo- and copolymers of [R]- $\beta$-hydroxyalkanoic acids, are produced by a wide variety of bacteria as an intracellular carbon and energy reserve [1,2]. Other environmental factors on which the fermentation medium depends are nature and concentration of the substrate used as carbon and energy source, presence and concentration of other nutrients in the culture medium, temperature, $\mathrm{pH}$, dissolved oxygen concentration, cultivation system. These factors influence the growth rate of the microorganism, cell density at the end of fermentation, substrate grade conversion and intracellular PHA content [3,4]. Depending on the number of carbon atoms, contained by the monomers units, PHAs isolated can be classified as follows: (i) short chain length $(\mathrm{scl})$ PHAs -3 to 5 carbon atoms/monomer, (ii) medium chain length $(m c l)$ PHAs -6 - 14 carbon atoms/monomer, and scl-co- $m c l$ with repeat-unit monomers containing 314 carbon atoms [2]. Many studies confirmed that scl-PHA type is much more flexible and resistant than $s c l$-PHAs $[5,6]$.

Due to their properties, similar to those of conventional plastics and their biodegradability, PHAs have attracted much interest as alternatives to synthetic polymers [8]. These are promising materials due to their useful characteristics: thermoplastic and elastomeric properties, biodegradability, biocompatibility and nontoxicity. Consequently, they are good candidates for Chem. Proc. 2020, 1, Firstpage-Lastpage; doi: FOR PEER REVIEW www.mdpi.com/journal/chemproc 
various applications in industry (replacements for petroleum-derived plastics, packaging industry, laminate papers and cardboards), fine chemical industry (starting materials for the synthesis of antibiotics and other fine chemicals) or medicine (scaffolds for bone tissue engineering, drug delivery system) [7,9-11].

In this paper, we studied the optimal concentration of fatty acids to obtain new biomaterials used in medical domain.

\section{Experimental}

\subsection{Materials}

Components of nutritive media were purchased from Merck (Kenilworth, NJ, USA) and SigmaAldrich (St. Louis, MO, USA), organic solvents, analytical reagents and mineral salts, from Merck, except for methyl esters of 3-hydroxy acids (C6-C11), purity 98\% purchased from Larodan, Sweden.

The PHA producing microorganism was Pseudomonas putida ICCF 391. The stock culture was grown at $29 \pm 1^{\circ} \mathrm{C}$ and maintained by periodic transfer on M44 (cDSMZ424) agar slants.

\subsection{Methods}

\subsubsection{Inoculum Growth Medium and Cultivation Conditions}

The pre-inoculum medium had the following composition ( $\% \mathrm{~g} / \mathrm{vol})$ : yeast extract $1.0 \%$, peptone $1.0 \%$, glycerol $5.0 \%$, agar $2.0 \%$. All the components were dissolved in distilled water, $\mathrm{pH}$ adjusted to 6.5, then sterilized at $120^{\circ} \mathrm{C}, 20 \mathrm{~min}$. Stock cultures were stored at $4{ }^{\circ} \mathrm{C}$. The inoculum containing (\% $\mathrm{g} / \mathrm{v}$ ): glucose $1.00 \%$, corn extract $1.50 \%, \mathrm{KH}_{2} \mathrm{PO}_{4} 1.00 \%, \mathrm{NaCl} 1.00 \%, \mathrm{MgSO}_{4} 0.05 \%$ was sterilized at $115^{\circ} \mathrm{C}$, for $20 \mathrm{~min}$. The inoculum was developed in $500 \mathrm{~mL}$ shake flasks (100 mL medium), at $29 \pm 1$ ${ }^{\circ} \mathrm{C}$ and $220 \mathrm{rpm}$ for $24 \mathrm{~h}$.

\subsubsection{Biosynthesis Conditions}

Batch fermentations were performed in $750 \mathrm{~mL}$ Erlenmeyer flasks, containing $250 \mathrm{~mL}$ of fermentation medium. Bioprocess medium had the following composition in mineral salts: $\mathrm{NaNH}_{4} \mathrm{HPO}_{4} \cdot 4 \mathrm{H}_{2} \mathrm{O} 3.5 \mathrm{~g} / \mathrm{L}, \mathrm{K}_{2} \mathrm{HPO}_{4} 7.5 \mathrm{~g} / \mathrm{L}, \mathrm{KH}_{2} \mathrm{PO}_{4} 3.7 \mathrm{~g} / \mathrm{L}$, structural correlated carbon source (sodium hexanoate, heptanoate, octanoate and nonanoate) $0.835-2.5 \mathrm{~g} / \mathrm{L}$, trace element solution I 1.0 $\mathrm{mL} / \mathrm{L}$, trace element solution II $1.0 \mathrm{~mL} / \mathrm{L}$ [12]. Trace element solution I contains $120.0 \mathrm{~g} / \mathrm{L} \mathrm{MgSO} \cdot 7 \mathrm{H}_{2} \mathrm{O}$. Trace element solution II contains per litre: $2.78 \mathrm{~g}$ of $\mathrm{FeSO}_{4} \cdot 7 \mathrm{H}_{2} \mathrm{O}, 1.47 \mathrm{~g}$ of $\mathrm{CaCl} 2 \cdot 2 \mathrm{H}_{2} \mathrm{O}, 1.98 \mathrm{~g}$ of $\mathrm{MnCl}_{2} \cdot 4 \mathrm{H}_{2} \mathrm{O}, 2.81 \mathrm{~g}$ of $\mathrm{CoSO}_{4} \cdot 7 \mathrm{H}_{2} \mathrm{O}, 0.17 \mathrm{~g}$ of $\mathrm{CuCl}_{2} \cdot 2 \mathrm{H}_{2} \mathrm{O}$, and $0.29 \mathrm{~g}$ of $\mathrm{ZnSO} 4 \cdot 7 \mathrm{H}_{2} \mathrm{O}$ in $1 \mathrm{M} \mathrm{HCl}$. The sterilized fermentation medium (as mentioned above) was inoculated with $10 \%(\mathrm{v} / \mathrm{v})$ preculture and incubated at $300 \mathrm{C}$, for $48 \mathrm{~h}$, on a rotary shaker, at $220 \mathrm{rpm}$. At 0 and $24 \mathrm{~h}$ of cultivation, the medium was supplemented with fatty acids investigated (C6, C7, C8 and C9), in different combinations. The cultivation was performed in two steps of nutrient addition. Optical density (OD) of cell suspension was measured at $\lambda=550 \mathrm{~nm}, 1: 25$ dilution, with a UV-VIS spectrophotometer Jasco V-Able 630. The quantity of dry biomass was determined with a thermobalance A \& D, MF-50.

\subsubsection{Post-Biosynthesis Processing}

At the end fermentations for biopolymer, isolation was carried out according to following steps: biomass separation through centrifugation; methanol pretreatment and vacuum drying of separated biomass; acetone Soxhlet extraction of $\mathrm{mcl}$-PHA from biomass using biomass: acetone ratio of 1:20; concentration of acetone extract at $1 / 4$ of the initial volume; mcl-PHA precipitation with cold methanol at a ratio of 1:10 concentrated extract: methanol; chloroform dissolution of precipitated $m c l$-PHA; slow evaporation of $m c l$-PHA chloroform solution [2]. 


\subsection{4. mcl-PHAs Assay}

The gas chromatographic method used for the determination of the polymers obtained by laboratory fermentations with the three bacterial strains above mentioned consisted of a mild acid methanolysis of the polymers followed by gas chromatography of the resulted methyl ester mixture [13]. The polymer composition and purity degree resulted by summing all of the contained monomers, determined by GC-FID. For the monomer composition determination, a capillary column has been used with an HP 5 (5\% phenyl-methylpolysiloxane) stationary PHAs. Methyl esters of C6C11 hydroxy acids have been used as standard substances.

\section{Results and Discussion}

\subsection{PHAs Bacterial Biosynthesis}

Several experiments were performed going through all the specific stages of a microbial biosynthesis process. We tested the evolution of the fermentation process for different precursor additions, namely: $\mathrm{C} 8, \mathrm{C} 9$ and combinations of $\mathrm{C} 8-\mathrm{C} 9, \mathrm{C} 6-\mathrm{C} 8, \mathrm{C} 7-\mathrm{C} 9$ added at different times of the bioprocess. The evolution of fermentation was followed by measurements of $\mathrm{pH}$, optical density and dry cell weight, as shown in Table 1.

Table 1. Fermentations in system fed batch for PHA biosynthesis.

\begin{tabular}{|c|c|c|c|c|c|}
\hline \multirow{2}{*}{ Samples } & \multicolumn{2}{|c|}{ Precursors Added (g/L) } & \multicolumn{3}{|c|}{ Fermentation Evolution } \\
\hline & $\mathbf{O h}$ & $24 \mathrm{~h}$ & $\mathrm{pH}$ & $\mathrm{OD}^{1}$ & $\mathrm{DC}^{2}(\mathrm{~g} / \mathrm{L})$ \\
\hline P5 & $8.35 \mathrm{C} 8$ & $8.35 \mathrm{C} 8$ & 7.32 & 0.5198 & 3.708 \\
\hline P7 & $8.35 \mathrm{C} 9$ & $8.35 \mathrm{C} 9$ & 7.35 & 0.241 & 1.619 \\
\hline P13 & $8.35 \mathrm{C} 8$ & 8.35 C9 & 7.16 & 0.353 & 1.619 \\
\hline P14 & $8.35 \mathrm{C} 9$ & $8.35 \mathrm{C} 8$ & 7.15 & 0.422 & 1.648 \\
\hline P17 & 8.35 C9 & $8.35 \mathrm{C7}$ & 7.19 & 0.287 & 9.795 \\
\hline P18 & $8.35 \mathrm{C} 7$ & $8.35 \mathrm{C} 9$ & 7.25 & 0.300 & 8.025 \\
\hline P19 & $8.35 \mathrm{C} 8$ & $6.88 \mathrm{C} 6$ & 7.37 & 0.527 & 8.727 \\
\hline P21 & $6.88 \mathrm{C} 6$ & $8.35 \mathrm{C} 8$ & 7.31 & 0.353 & 6.147 \\
\hline
\end{tabular}

Correlating the data from the experiments performed, we noticed that using a mixture of 2 precursors a higher amount of dry biomass $(\mathrm{g} / \mathrm{L})$ was obtained, compared to the fermentation in which a single precursor was used (C8 or C9).

\subsection{PHAs Extraction}

Following the processing of biomass and the isolation of PHAs by the mentioned methods, yields between 53 and 56\% were achieved depending on the polymer content of the dry cells. The composition and purity of polymers isolated were determined by GC-FID and expressed in $\mathrm{g} / 100 \mathrm{~g}$ of analyzed product (Table 2).

Table 2. Experimental values obtained for PHAs biosynthesized.

\begin{tabular}{|c|c|c|c|c|c|c|c|}
\hline \multirow[b]{2}{*}{ Samples } & \multirow{2}{*}{$\begin{array}{c}\text { PHAs } \\
(\%)\end{array}$} & \multicolumn{6}{|c|}{ Hydroxyacids } \\
\hline & & $\begin{array}{c}\text { C6 } \\
(\%)\end{array}$ & $\begin{array}{c}\text { C7 } \\
(\%)\end{array}$ & $\begin{array}{c}\text { C8 } \\
(\%)\end{array}$ & $\begin{array}{c}\text { C9 } \\
(\%)\end{array}$ & $\begin{array}{l}\text { C10 } \\
(\%)\end{array}$ & $\begin{array}{l}\text { C11 } \\
(\%)\end{array}$ \\
\hline P5 & 51.16 & 7.32 & - & 88.00 & 3.29 & 1.29 & - \\
\hline P7 & 40.40 & 1.25 & 21.58 & 13.23 & 59.63 & 0.75 & 0.47 \\
\hline P13 & 47.66 & 2.91 & 13.57 & 33.79 & 45.72 & 0.93 & 0.86 \\
\hline P14 & 35.81 & 1.33 & 19.55 & 14.9 & 59.59 & 1.44 & 0.77 \\
\hline P17 & 43.22 & 0.11 & 14.23 & 0.36 & 79.32 & 1.44 & 2.54 \\
\hline P18 & 48.79 & - & 66.18 & 0.52 & 26.77 & 2.20 & 0.57 \\
\hline
\end{tabular}




\begin{tabular}{llllllll}
\hline P19 & 56.29 & 9.66 & - & $\mathbf{7 9 . 4 6}$ & 0.13 & 7.59 & 0.96 \\
\hline P21 & 52.64 & 8.28 & - & $\mathbf{8 2 . 6 5}$ & - & 5.53 & 1.08 \\
\hline
\end{tabular}

The analytical results show that by biosynthesis, isolation and purification of PHAs, using different precursors co-polymers with other content of monomers were obtained ranging between 66.18 for $\mathrm{C} 7,79.46-88 \%$ for $\mathrm{C} 8,45.72-79.32 \%$ for C9.

From all the precursor amount used up by microorganism during the fermentation, $16.70 \mathrm{~g}(8.35$ $\mathrm{g} / \mathrm{L}$ in the fermentation medium), 1.619-9.795 g/L dry bacterial biomass and 0.54-1.95 g/L PHA, containing mostly PHO were obtained (Figure 1).

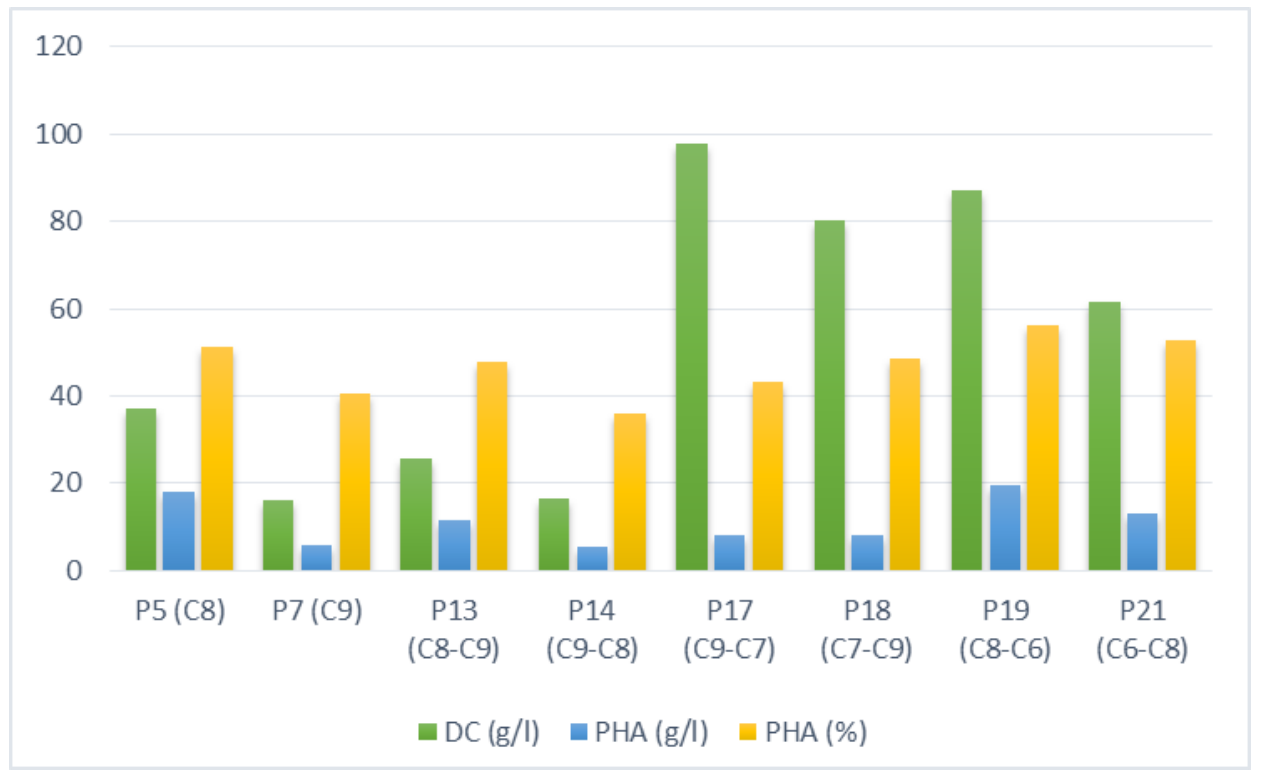

Figure 1. Biomass and mcl-PHAs production by Ps. putida.

\section{Conclusions}

Following the studies performed to obtain mcl-PHAs, several sets of experiments were performed that followed the effect of each of the C6-C9 fatty acids and their combinations. The results showed the optimal conditions and the maximum limit of metabolism with four fatty acids and the ability of the microorganism to metabolize octanoic acid easier and more productive than the other three fatty acids, these results are further verified in the experimental model of biosynthesis and processing to obtain PHAs. The results revealed the performance of the microorganism to produce mcl-PHA by converting the monomers tested as precursors to a maximum limit of $16.70 \mathrm{~g} / \mathrm{L}$. Thus, polymers containing (in percentage) $66.18 \mathrm{C} 7$, from 79.46 to $88 \mathrm{C} 8$, from 45.72 to $79.32 \mathrm{C} 9$.

And following the obtained results, an in-depth study of these biopolymers can be continued for their use as a material in the electrospinning method to obtain fibres and scaffolds for tissue engineering applications.

Acknowledgments: The work has been funded by the Operational Programme Human Capital of the Ministry of European Funds through the Financial Agreement 51668/09.07.2019, SMIS code 124705. This work was supported by the Ministery of Education and Scientific Research, the Grant number: PN 19-41 041 01/2019.

\section{References}

1. Bhushaniab, J.A.; Anandharamakrishnan, C. Trends Food Sci. Technol. 2014, 38, 21-23.

2. Lupescu, I.; Eremia, M.C.; Savoiu, G.V.; Spiridon, M.; Panaitescu, D.; Nicolae, C.; Vladu, M.G.; Stefaniu, A. Comparative studies on isolation of medium-chain-length Polyhydroxyxyalkanoates produced by Pseudomonas spp. strains. Rev. Chim. 2016, 67, 1957-1962.

3. Vladu, M.G.; Petrescu, M.M.; Stefaniu, A.; Savoiu, G.; Maria, S.; Eremia, M.C.; Lupescu, I. Studies on polyhydroxyalkanoates biosynthesis by some Pseudomonas spp. strains. Rom. Biotechnol. Lett. 2019, 24, 4149. 
4. Muangwong, A.; Boontip, T.; Pachimsawat, J.; Napathorn, S.C. Medium chain length polyhydroxyalkanoates consisting primarily of unsaturated 3-hydroxy-5-cis-dodecanoate synthesized by newly isolated bacteria using crude glycerol. Microb. Cell Factories 2016, 15, 55.

5. Cirstea, D.M.; Stefanescu, M.; Pahonţu, J.M.; Cornea, C.P. Use of some carbon sources by Pseudomonas strains for synthesizing polyhydroxyalkanoates and/or rhamnolipids. Rom. Biotechnol. Lett. 2014, 19, 94009408.

6. Kabilan, S.; Ayyasamy, M.; Jayavel, S.; Paramasamy, G. Pseudomonas sp. as a source of medium chain length polyhydroxyalkanoates for controlled drug delivery: Perspective. Int. J. Microbiol. 2012, doi:10.1155/2012/317828.

7. Ali, I.; Jamil, N. Polyhydroxyalkanoates: Current applications in the medical field. Front. Biol. 2016, 11, 1927.

8. Koller, M. Poly(hydroxyalkanoates) for Food Packaging: Application and Attempts towards Implementation. Appl. Food Biotechnol. 2014, 1, 3-15.

9. Volova, T.; Goncharov, D.; Sukovatyi, A.; Shabanov, A.; Nikolaeva, E.; Shishatskay, E. Electrospinning of polyhydroxyalkanoate fibrous scaffolds: Effects on electrospinning parameters on structure and properties. J. Biomater. Sci. Polym. Ed. 2013, 25, 370-393.

10. Puppi, D.; Pecorini, G.; Chiellini, F. Biomedical Processing of Polyhydroxyalkanoates. Bioengineering 2019, $6,108$.

11. Li, Z.; Lim, J. Biodegradable polyhydroxyalkanoates nanocarriers for drug delivery applications. In Stimuli Responsive Polymeric Nanocarriers for Drug Delivery Applications Volume 1; Woodhead Publishing: Sawston, UK; Cambridge, UK, 2018; pp. 607-634.

12. Vladu, M.G.; Petrescu, M.M.; Stefaniu, A.; Savoiu, G.; Spiridon, M.; Eremia, M.C.; Lupescu, I. Studies on polyhydroxyalkanoates biosynthesis by some Pseudomonas spp. strains. Rom. Biotechnol. Lett. 2019, 24, 388394.

13. Koller, M.; Hesse, P.; Bona, R.; Kutschera, C.; Atlic, A.; Braunegg, G. Biosynthesis of High Quality Polyhydroxyalkanoate Co- and Terpolyesters for Potential MedicalApplication. Macromol. Symp. 2007, 253, 33-39.

Publisher's Note: MDPI stays neutral with regard to jurisdictional claims in published maps and institutional affiliations.

(C) 2020 by the authors. Submitted for possible open access publication under the terms and conditions of the Creative Commons Attribution (CC BY) license (http://creativecommons.org/licenses/by/4.0/). 